\title{
How Good Are Child Vulnerability Assessment Tools in China?
}

\author{
Di Qi ${ }^{1, *}$ and Shiyou $\mathrm{Wu}^{2}$ D \\ 1 Department of Sociology, School of Public Administration, Hohai University, Nanjing 211100, China \\ 2 School of Social Work, Arizona State University, Pheonix, AZ 85004, USA; shiyou.wu@asu.edu \\ * Correspondence: qidi@hhu.edu.cn
}

Received: 27 June 2020; Accepted: 7 July 2020; Published: 8 July 2020

\begin{abstract}
Accurately assessing children's vulnerabilities and needs is important for child service delivery in social work. In China, different agencies (including international non-governmental organizations, government sectors and social organizations) utilize different tools for assessing children's needs. However, the advantages and disadvantages of these tools have been rarely discussed, leaving their quality and effectiveness unknown. As a result, it is difficult to realize the goal of improving the well-being of Chinese children. This paper contributes to existing knowledge through the use of semi-structured interviews with key stakeholders of different types of agencies, along with an in-depth exploration, analysis and comparison of their practical assessment tools.
\end{abstract}

Keywords: assessment tool; child well-being; evaluation; effectiveness; China; vulnerable children

\section{Introduction}

Addressing the needs of vulnerable children is an important but challenging process (Arbeiter and Toros 2017; Toros 2016; Välba et al. 2017). It calls for accurate assessment of children's vulnerabilities and needs. The assessment process has been recognized as being a complicated social process. This is because so many different actors are involved in the assessment process (including child welfare/protection social workers, children and their families, and those familiar with the situation of children-such as extended family members). In order for child protection or welfare social workers to make accurate assessment decisions about a child and his/her family, it is important that the assessment process links with service provision and child vulnerabilities.

Recently in China, there has been growing attention from both the government and the public about vulnerable children and the relevant institutional resources allocated to them for addressing their most urgent needs. The most influential policy guideline for the protection of vulnerable children's rights is currently the Guideline on Protection of Vulnerable Children in China, promulgated by the State Council of the Chinese Government (State Council 2016). It clearly sets out the goals to protect the basic rights of vulnerable children. The target populations include: Children in poor households with difficult living conditions (such as those with little healthcare provision or with limited educational opportunity); children with severe illness; and children without proper guardianship (suffering harm due to abuse, abandonment, accidental harm or illegal attack). For these groups of vulnerable children, the responsibility of assessing their vulnerabilities, needs and social service requirements mainly falls to local government and social work organizations.

Obviously, different organizations use different tools for assessing children's needs. However, the advantages and disadvantages of these applied assessment tools have rarely been discussed. As a result, it is particularly important that the following questions be answered. What assessment tools are used by Chinese social organizations for assessing children's vulnerabilities? What dimensions and indicators are used in existing tools? What are the advantages and disadvantages of Chinese 
social workers using a particular child assessment tool or instrument? To date, few studies have systematically analyzed existing assessment tools used by social workers to assist vulnerable children in China. Therefore, it is difficult to realize the goal of improving the well-being of children. This paper contributes to existing knowledge through semi-structured interviews with key stakeholders of social work organizations, coupled with in-depth exploration, analysis and comparison of their practical assessment tools.

\section{Literature Review}

Comprehensive assessments of children and families in need have become popular in child welfare provision. They are defined as the process of identifying, gathering and weighing information so as to understand children's safety, permanency, well-being, parental capabilities, family's abilities as well as the underlying risk factors (Darlington et al. 2010; Johnson et al. 2008; Léveillé and Chamberland 2010; Rosanbalm et al. 2016; Smithgall et al. 2015). Compared with limited assessment of children's vulnerabilities, a comprehensive assessment can often better assess the child's situation and his/her vulnerabilities, in order to provide appropriate service delivery. For an assessment to be comprehensive, it should satisfy the requirements in a broad coverage of the domains and an in-depth understanding of the context. Specifically, a comprehensive assessment refers to a broad examination of children's developmental and behavioral needs, and the needs of people involved in the children's lives (such as parents, siblings, extended family, the community and the school). It also requires a better understanding of the history, duration and context of the child's problems, as well as the nature of relationships which prevent a child's well-being. Furthermore, assessment tools should also be valid and reliable.

It has been summarized that the most valid and reliable assessment tools should incorporate the following domains as a minimum:

- Patterns of social interaction (including the nature of contact and involvement with others, and the presence or absence of social support networks and relationships);

- Parenting practices (including parenting supervision, discipline, knowledge of child development, knowledge of the emotional needs of the child);

- Background history of the parents or caregivers (including any history of abuse and neglect), and;

- Problems in accessing basic necessities such as income, employment adequate housing, child care, transportation and other needed services or support (Johnson et al. 2008).

Previous studies have compared the content and the quality of different assessment tools (Léveillé and Chamberland 2010), and examined the effectiveness of the assessment tools (Smithgall et al. 2015). For example, Léveillé and Chamberland (2010) systematically evaluated the experiences of needy children and their family framework. Smithgall et al. (2015) systematically analyzed the quality of child assessment reports by reviewing the assessment process and evaluating its quality. The analysis included the following factors: Whether a report has a clear timeline, whether it is well-organized, has supporting evidence, assesses patterns over time, and whether it considers the family perspective. It also examined factors influencing child assessment quality such as resource allocation from social work organizations. Earlier work by Gambrill and Shlonsky (2000), also discussed potential issues arising when caseworkers misunderstand key terms in the assessment procedure and how this influences professional judgement or the assessment of the clients' situation. Arbeiter and Toros (2017) posit that parental engagement in the assessment process is important for identifying a child's social services' needs, which in turn calls for effective engagement strategies between social workers and parents.

The studies discussed above cover a wide range of assessment related issues. However, few studies have examined how the vulnerability of Chinese children in the People's Republic of China is assessed by domestic caseworkers. Even fewer studies have compared Chinese assessment tools by analyzing their structure, quality and effectiveness. Therefore, this paper will examine how child assessment tools 
are developed in a Chinese social context. It will investigate what tools are used to assess children's vulnerabilities, their differences and similarities. It will also assess how social workers in different social settings implement vulnerability assessments. The advantages and disadvantages of assessment instruments utilized by different social work organizations will also be discussed and compared.

\section{Methodology}

Setting. To address the proposed research questions, a qualitative in-depth case study method was adopted, as this approach yields more detailed information with respect to the research questions (Flyvbjerg 2006). Face-to-face semi-structured interviews with key stakeholders from three social work organizations were used to gather raw data. These different types of agencies were used to capture a more holistic view about Chinese assessment instruments. The three social organizations/agencies were: (a) An international non-governmental organization (INGO), hereafter INGO (name withheld); (b) a government agency located in Jiangsu Province in eastern China, hereafter Agency G; and (c) a domestic social work organization in Beijing, hereafter Agency L. In total, three key stakeholders from the INGO, Agency G and Agency L were interviewed; namely the child protection officer, the Ministry of Civil Affairs section chief, and the agency counselor, respectively. Additionally, agency documentation relevant to child well-being and vulnerabilities (such as national/provincial policy guidelines and agency policy references) were reviewed.

Data collection. Data was collected between January and March 2019. To examine the advantages and disadvantages of different assessment instruments used by social workers in practice, and evaluating the effectiveness of the practical assessment framework, the following four research questions were used: (a) What assessment tools/instruments are employed?, (b) what is the purpose of using these instruments?, (c) what domains are used for assessing children's vulnerabilities?, and $(\mathrm{d})$ are these instruments effective?

The interviewer also asked follow-up questions to clarify meaning or participant responses. All interviews were audio-taped with participant consent. Each interview lasted 90 min, participants were interviewed just once and did not receive compensation for their time. All interviewees were informed of the purpose of the study, that their participation was voluntary and that they could withdraw their participation at any point during the interview process. Interviews with key stakeholders were necessary so as to provide more in-depth background information from each agency. This assisted our understanding of how and why a particular assessment tool was developed or applied, which indicators were used, and how effective the tools were. All this information helps to develop the research themes and concepts.

Data Analysis. Audiotapes of interviews were first transcribed and then checked by the interviewees to confirm accuracy. Based on a grounded theory approach (Glaser and Strauss 1967), the research team developed codes and a constant-comparative process to establish themes (Creswell 2012; Ritchie et al. 2013). This was achieved by manually coding quotations that can be combined as a common concept from the three agencies' interview transcripts. The coded quotations were compared to other similar quotations in the subsequent coding process. This comparison enhanced the consistency of each code. Two coders independently conducted the coding process. The research team then examined the codes together, and discussed any inconsistencies, in order to ensure the accuracy of the codes (Wu et al. 2016). The codes were later synthesized into clusters of common themes, discussed in the main research findings.

\section{Findings}

The INGO uses a simple and quick assessment in order to identify children's urgent needs. In order to explore child welfare delivery at the grass-roots level, the INGO piloted a child welfare project in Shanxi, Henan, Sichuan, Yunnan and Xinjiang. This project, which commenced in May 2010, has been one of the most influential child welfare projects in China in recent years. The aim of the project was to accurately understand and evaluate the welfare needs of vulnerable children, 
so as to provide appropriate delivery of social services. The term 'children in distress' was used to describe the vulnerable children with special needs, including orphans, children with disabilities, single-parent children, left-behind children, street children, delinquent children, children living in poverty, children with serious illnesses, and undocumented children (meaning children who do not have any official identity papers such as a Hukou registration certificate). Child welfare caseworkers at the INGO working with these vulnerable children were required to assess both the children and their family's situation to help identify children's needs. An assessment tool was designed to identify the key challenges/vulnerabilities faced by the children, in order to allocate social services and institutional resources. Table 1 contains a summary of the assessment tool used by social workers in the INGO supported project.

Table 1. The dimensions and indicators of the assessment tools of the INGO supported Child Welfare Project in China.

\begin{tabular}{ccl}
\hline Dimension & & \\
\hline $\begin{array}{c}\text { Child Health } \\
\text { (Assessment }\end{array}$ & - & Whether or not children are physically or mentally healthy; \\
Tool Form A) & - & Whether or not children have medical needs or needs for psychological counselling; \\
\hline Child & Whether or not children have needs for employment & About children's academic performance; \\
Education & - & $\begin{array}{l}\text { About children's peer relationships; } \\
\text { About the school safety; }\end{array}$ \\
Family & - & Whether or not parents have proper nurturing knowledge; \\
Environment & - & $\begin{array}{l}\text { Whether or not parents have proper nurturing behaviors; } \\
\text { Whether or not economic conditions could satisfy children's basic needs for survival } \\
\text { and education; }\end{array}$ \\
\hline $\begin{array}{c}\text { Assessment } \\
\text { (Form B) }\end{array}$ & $\begin{array}{l}\text { The following needs have been identified by the assessment form including children's } \\
\text { needs for household registration, basic living needs, healthcare needs, educational needs, } \\
\text { safe protection needs, psychological needs, employment or training needs and other family } \\
\text { members' needs }\end{array}$ \\
\hline
\end{tabular}

Note: The Form A is the assessment form for assessing children's situations and Form B is one specific form for further identifying children's urgent needs in multiple domains. Source: Guidelines of the Child Welfare Pilot Project (2014).

In total, the INGO applied two sets of assessment tools for village children. One set of tools was used to screen out the key vulnerabilities faced by children in the areas of healthcare, education and family background. The second set of tools was used to identify the village children's needs. As noted above, these two sets of assessment tools were used by the child welfare caseworkers to assess the situation of vulnerable children so that appropriate resources and services could be delivered. For example, the first set of tools was comprised of a Form A (the Form A is the assessment form for assessing children's situations) and a Form B for further identifying children's urgent needs in multiple domains (see Table 1). The Form B mainly focused on assessing the domains of children's health, education, parenting nurturing and family environment. Form B attempts to yield the most important vulnerabilities that children experience. As the agency staff discussed,

'At the grass-roots level, there are insufficient staff responsible for child social work. It is also difficult to promote child welfare without professional social workers. In recent years, we [the INGO] have worked to establish a "child welfare director" system, whereby the child welfare director in the village is actually the social worker. This resolves the problem of insufficient numbers of trained social workers.

Our project pays the child welfare director for their professional services. With the right incentives, we can hire some person suitable for this job. They are responsible for assessing children and the situation of their family, identifying the child's welfare needs, making detailed service plans, 
and sourcing assistance for the most disadvantaged children in the village. The duties of the child welfare director are heavy, making it impossible to provide complex assessments for vulnerable children and their families. The assessment form they use is purposely kept simple. It contains only the most important information so as to reduce the time needed to make an assessment.'

In summary, given the shortage of the available social workers, instead of using a comprehensive assessment tool, the INGO adopted a brief assessment tool to assess the most vulnerabilities experienced by children and their families. This is more cost-effective, and helps to address children's needs in a short time. However, the INGO's brief assessment tool has several drawbacks.

First, the indicators used on evaluation Form A are inconsistent with the corresponding form for evaluating a child's welfare and protection needs (Form B: Child Welfare and Protection Services' Needs Evaluation Form). The Form A assessed the domains of child health (such as children's physical or mental health), education (such as children's academic performance or peer relationships) and family environment (such as parents' nurturing knowledge or behaviors). Whereas, the design of the Form B evaluation tool aims to identify children's needs by asking whether any of the following services are required: Household registration, basic living assistance, healthcare provision, education, personal safety, psychological health, parental employment/skills training. Parental knowledge of how to raise their children (hereafter "nurturing"), nurturing behaviors or strong healthy relationships with their children (as identified originally in the Form A evaluation tool) were missing or at least were not clearly reflected on the corresponding Form B. Therefore, there is a mismatch between the assessment tool of the vulnerabilities and the assessment tool of the needs.

Second, the coverage of domains was limited with only three dimensions assessed, including child health, education, and family environment. Children have multiple needs in survival and development. According to the criteria of being a comprehensive assessment tool, this tool has not met the requirements of having a broad coverage of the domains because very few domains were assessed. Nor does the Form B examine either the duration of challenging issues faced by the children, or explore the relationships between different issues. Therefore, the assessment by the INGO does not meet the requirements of assessment in breadth (the broad coverage of dimensions) and depth (the deep understanding of the context).

Agency $\mathrm{G}$ adopts a classified assessment approach to identify vulnerable children. However, the classification indicators need to be refined. The local civil affairs bureau developed tools for assessing problems experienced by children in distress. The aim was to better identify children's needs and to provide appropriate social services. The Chinese central government has classified vulnerable children based on the following three types of risk factors: (a) Child individual-level risk factors, (b) parental-level risk factors, and (c) household-level risk factors. The children at risk include those without parental care or a guardian (e.g., where parents are migrant workers, deceased, unknown, in prison or undertaking compulsory drug treatment), children distressed due to illness, disability, and poverty. The children at risk in any of the situations above are identified as the "vulnerable child group". In practice, local governments generally follow the identification criteria used by the national government so as to screen out vulnerable children. They then use their own local assessment tools to produce an in-depth assessment of the key challenges faced by these children.

Agency $\mathrm{G}$ is a typical city level organization that has pioneered practical assessment instruments, based on the central government criteria outlined above. Agency G pioneered two sets of assessment instruments. The first set tool was used to assess the risks/challenges faced by children in distress and to identify these children's social service provision needs. In 2014, the Agency G collaborated with a child foundation to promote its child protection scheme and applied this tool. The most obvious function of the tool was to identify those children at high risk from a larger cohort of vulnerable children. The tool assessed the following areas:

- Previous experience of physical/sexual abuse;

- Neglect; 
- High risk of being harmed;

- Difficulties faced at school;

- Physical, mental and emotional status of parents or a guardian;

- Nurturing skills of parents or a guardian;

- History of abuse or neglect in the family;

- Social support provided by the larger family, and;

- The household environment.

This first set assessment tool focuses on child protection. It also pays more attention to the risks of child abuse and neglect. It is therefore argued that this tool has a narrow rather than a broad coverage, and therefore does not meet the first criteria of being a comprehensive assessment tool. However, the tool permits an in-depth understanding of family/guardian history and therefore, satisfies the second criteria of being a comprehensive assessment tool.

The second set of assessment tools developed by the Agency G have a wider focus on child well-being, with a strong focus on identifying the child's needs for social services. These so-called "casework service assessment tools", assess the requirement from the following perspectives:

- Child emotional management status;

- Relationships with friends and teachers;

- Household sanitary conditions;

- Household safety;

- Educational status and self-management skills, and;

- The needs for household services.

This set of tools also focuses on parental employment and parenting skills. For a better assessment of the needs of the vulnerable children and the allocation of appropriate social services, Agency $G$ also developed a classification assessment instrument, the "Vulnerable Children Casework Classification Indicator" (it is another instrument, a special classification tool, in addition to the two tools described above). This indicator tool classifies children into four groups based on the level of risk faced by the child: Group A, group B, group C and group D. The group A children include those suffering from the highest risks or challenges, followed by group $\mathrm{B}$ and group $\mathrm{C}$ children at lower risk, and group $\mathrm{D}$ children at lowest risk. For example, children in any of the following circumstances will be placed in group A: (a) Children without guardship; (b) suspected victims of violence (sexual/mental/physical violence or neglect); (c) disabled children without proper family care; (d) children suffering from severe illness and lacking proper family care; and (e) other types of children requiring risk intervention.

For children placed in group B, proper family care and the ability of the child's guardian are the most important factors to consider. Children in the following situations will be placed in the group B: (a) Children suffering from mental or physical illness without family/social support, (b) the child's guardian suffers from mental or physical illness to the extent that they cannot provide proper care for the child; (c) a family history of violence, abuse, suicide or running away from home; (d) the guardian has weak nurturing skills which negatively affect the child's development; and (e) the child does not have two biological parents (e.g., single parent families), or the family is unable to provide a safe, stable home environment.

According to the child welfare director, this classification assessment tool has been used by Agency G since 2018. He opined that:

'We set up this classification system in order to streamline the delivery of services for vulnerable children. These children are suffering from many risks, issues and challenges in their daily lives. However, different children have different combinations of risks and therefore require different resources to address their needs. Of course we want to quickly identify these most disadvantaged groups in order to provide the requisite help and services for them.' 
The assessment tools used by the Agency G give different weightings to the child vulnerabilities listed above. It achieves this by placing more emphasis on child guardianship and the characteristics of the guardian. This contributes to assessment effectiveness by classifying children into different groups according to the risks and challenges faced. Thus, children classified in groups A, B, C and D (that is, by risk) would be provided with different levels of social service and/or protection. Using these classification tools, services can be delivered to children more accurately and effectively. However, further research needs to find out whether the classification indicators are appropriate for classifying children. It is also necessary to refine the classification process to make outcomes more convincing and less open to interpretation.

Agency L uses a more comprehensive assessment procedure to provide quality services, but the continuity of the services depends on external factors (e.g., the financial and human resources of the agency). In addition to INGOs and government agencies, local social service agencies play a key role in both protecting children's basic rights and delivering social services to them. Agency L, based in Beijing's Xicheng district, is a typical local social services agency which has worked for many years to serve vulnerable children. Agency L developed its own assessment tool in order to better understand the challenges and vulnerabilities faced by children at risk. They used the term "children in distress" in their fieldwork, but identified this group of vulnerable children in a different way compared with Agency G. Instead, vulnerable children are grouped and identified according to policy guidelines issued by the municipal government. These vulnerable children include children experiencing poverty, orphans/children without a guardian or without proper care (e.g., left-behind children), homeless children, severely ill or disabled children, and children suffering from HIV. Although there are slight regional variations in defining the vulnerabilities faced by children across the country, vulnerabilities at child-, parental- and household-levels are commonly used factors for screening out the most vulnerable children. After screening vulnerabilities of children based on the government guidance noted above, local social services agencies then assess the child's vulnerabilities in depth, in order to provide services as needed. The director of Agency L commented that:

'The government gives us a list of poor and vulnerable children. The children named on the list are selected based on criteria outlined in government policy documents. The local government staff decide who will be on the list. The children on the list could actually be called our clients. Not only do they receive monetary assistance, protection and welfare, but they can also receive professional services offered by our social workers.'

At Agency L, three factors are considered when assessing challenges faced by disadvantaged children, including: (a) Children's individualized factors; (b) family background (e.g., socioeconomic status); and (c) social networking status. In contrast to the identification of vulnerabilities used by Agency G, Agency L gives greater weight to a child's individualized factors and family background. Agency $L$ also classified children into different groups according to the risks and challenges these children experience. Table 2 shows the indicators used for classifying high risk child cases.

Specifically, when firstly assessing a child's individualized factors, Agency L placed greater emphasis on the child's physical health, psychological condition and behavioral performance. Second, family background was evaluated by the following three conditions: (a) Household conditions, (b) household resources, and (c) caregivers' parenting ability. Lastly, less importance is given to the child's social networking status based on the child's educational achievement and the social ties (such as educational achievement or social relationships). Overall, more weight is given to a particular child's vulnerabilities and the ability of his/her household to provide care and protection. The total score summarizing all these factors ranges from 0 to 100 with a higher score representing a better quality of life and a lower score indicating higher risk. Children with the lowest scores are marked as a high risk group (e.g., in red). This indicates intense exposure to personal, family and/or social networking issues and thus requiring urgent action from social workers. Children with higher scores are placed in the pink and yellow groups, indicating a decreased likelihood of suffering from personal, 
familial and social networking problems (see Table 2 for more details). By this system of classification, social workers at Agency L have a better understanding of the risks for vulnerable children.

Table 2. Assessment Instrument of Agency L.

\begin{tabular}{ccc}
\hline Domains & Indicators & Scores \\
\hline \multirow{2}{*}{ Children's Personal Status } & Physical Harms and Health & 15 \\
\cline { 2 - 3 } & Psychological Status & 10 \\
\cline { 2 - 3 } Total Assessment Scores & Behaviors Performance & 10 \\
\hline \multirow{2}{*}{ Family's Status } & Family's System & 40 \\
\cline { 2 - 3 } & Family's Resources & 10 \\
\cline { 2 - 3 } Total Assessment Scores & Family's Care Ability & 10 \\
\hline Social Networking Status & Educational Status & 20 \\
\cline { 2 - 3 } & Social Networking Status & 10 \\
\hline Total Assessment Scores & & 20 \\
\hline Red Group & High-Risk Children & $0-75$ (total scores) \\
\hline Pink Group & Middle-Risk Children & $76-80$ (total scores) \\
\hline Yellow Group & Low-Risk Children & $81-90$ (total scores) \\
\hline
\end{tabular}

Additionally, Agency L utilizes in-depth assessment instruments when visiting children and their families. These instruments include a comprehensive family assessment tool, a home guidance booklet and a deep assessment formed by playing games with children where necessary. Table 3 summarizes the similarities and differences between the different tools used by Agency L and other social service organizations. In particular, the coverage of the domains and the level of understanding of the context of the assessment can be compared. The agency director argued that:

'The application of different assessment tools is important mainly for increasing the accuracy and effectiveness of assessment outcomes. Relying on one set of assessment instruments does not allow us to fully map the situation of vulnerable children. A combination of different tools allows us to double check assessment outcomes in specific domains and thus avoid subjective judgement by social workers.'

Table 3. Comparing assessment instruments by INGO, Agency L and Agency G.

\begin{tabular}{|c|c|c|c|}
\hline $\begin{array}{l}\text { Assessment } \\
\text { Domains }\end{array}$ & INGO & $\begin{array}{l}\text { Social Organization } \\
\text { (Agency L) }\end{array}$ & $\begin{array}{l}\text { Government Sector } \\
\text { (Agency G) }\end{array}$ \\
\hline $\begin{array}{l}\text { Child-Level: } \\
\text { Children's } \\
\text { Personal } \\
\text { Conditions }\end{array}$ & $\begin{array}{l}\text { Whether or not children are physically } \\
\text { or mentally healthy } \\
\text { Whether or not children have medical } \\
\text { needs or needs for } \\
\text { psychological counselling } \\
\text { Whether or not children have needs } \\
\text { for employment }\end{array}$ & $\begin{array}{ll}\text { - } & \text { Physical health } \\
\text { - } & \text { Psychological condition } \\
\text { - } & \text { Behaviors performance }\end{array}$ & $\begin{array}{l}\text { - } \quad \begin{array}{l}\text { Children suspected of } \\
\text { being victims of violence } \\
\text { (sexual/mental/physical }\end{array} \\
\text { violence or neglect) } \\
\text { - } \quad \text { Disabled children } \\
\text { - Children suffering from } \\
\text { severe illness }\end{array}$ \\
\hline $\begin{array}{l}\text { Family-Level: } \\
\text { Family } \\
\text { Conditions }\end{array}$ & $\begin{array}{l}\text { Whether or not parents have proper } \\
\text { nurturing knowledge } \\
\text { Whether or not parents have proper } \\
\text { nurturing behaviors } \\
\text { - Whether or not parents have } \\
\text { good relations } \\
\text { Whether or not economic conditions } \\
\text { could satisfy children's basic needs for } \\
\text { survival and education }\end{array}$ & $\begin{array}{ll}\text { - } & \text { Family system status } \\
\text { - } & \text { Resources condition } \\
\text { - } & \text { Caregiving status }\end{array}$ & $\begin{array}{l}\text { - } \quad \text { Without guardianship } \\
\text { - } \quad \text { Lack of proper care } \\
\text { from guardian } \\
\text { - } \quad \text { Lack of family } \\
\text { - } \quad \text { Locial support } \\
\text { Lack of nurturing skills }\end{array}$ \\
\hline
\end{tabular}


Table 3. Cont

\begin{tabular}{|c|c|c|c|}
\hline $\begin{array}{c}\text { Assessment } \\
\text { Domains }\end{array}$ & INGO & $\begin{array}{l}\text { Social Organization } \\
\text { (Agency L) }\end{array}$ & $\begin{array}{l}\text { Government Sector } \\
\text { (Agency G) }\end{array}$ \\
\hline $\begin{array}{l}\text { Additional } \\
\text { Dimension }\end{array}$ & $\begin{array}{l}\text { - Children's academic performance } \\
\text { - } \quad \text { Children's peer relationships } \\
\text { - } \quad \text { The school safety }\end{array}$ & $\begin{array}{ll}- & \text { Social networking } \\
\text { - } & \text { Educational status }\end{array}$ & $\begin{array}{l}\text { - The mental or physical } \\
\text { situations of other } \\
\text { family members }\end{array}$ \\
\hline Comments & $\begin{array}{l}\text { No classification, the breadth of this tool is } \\
\text { medium. It takes simpler format with the } \\
\text { advantage of facilitating quicker } \\
\text { assessment by social workers. Whereas, } \\
\text { some indicators have mixed the assessment } \\
\text { of children's vulnerabilities with their } \\
\text { service needs. }\end{array}$ & $\begin{array}{l}\text { Combined classification and } \\
\text { assessment, also utilized } \\
\text { other tools for achieving } \\
\text { accuracy, but the same set of } \\
\text { indicators for classifying } \\
\text { vulnerable children should } \\
\text { be improved. }\end{array}$ & $\begin{array}{l}\text { Combined classification and } \\
\text { assessment, also contained } \\
\text { tools for assessing service } \\
\text { needs; but this tool has given } \\
\text { greater weights to ability of } \\
\text { guardianship rather than } \\
\text { child-focused vulnerabilities. }\end{array}$ \\
\hline
\end{tabular}

\section{Discussion}

This study has collected qualitative data via semi-structured interviews with key stakeholders from a Chinese INGO, and government/social service agencies. The data collected focuses on the use of practical assessment instruments used by Chinese caseworkers. Each organization analyses children's individual circumstances with respect to physical and mental status, as well as the family situation. We argue that the data demonstrates the significance of assessing both the health status of children and the family context when assessing child vulnerabilities. According to research by Johnson et al. (2008), the most valid and reliable assessment tools should, as a minimum, incorporate social networking, parenting practices, the backgrounds of parents and caregivers, and the challenges faced in accessing basic facilities or services. The assessment tools used by the three agencies studied adequately cover these areas and can therefore be treated as valid and reliable.

However, the assessment tools used by the three agencies differ in content and function. According to the criteria of breadth (broad coverage of domains) and depth (the in-depth understanding of the context), the assessment tools used by the three agencies were different. The INGO assessment tools were used by child welfare directors in rural China with the aim of examining child risk/vulnerability. Achieving a quick and brief assessment was the key feature of the INGO tool, given their priority to address children's basic needs with only a limited number of trained social workers to implement the assessment. In contrast, Agency L and Agency G have adequate numbers of social workers trained in the assessment procedures. Therefore, they were able to conduct more comprehensive assessments which captured children's vulnerabilities more thoroughly. Coverage of the domains and obtaining an in-depth understanding of the child's background was better in Agencies G and L. Additionally, Agencies $\mathrm{G}$ and $\mathrm{L}$ have developed special assessment tools for classifying children into different risk groups, so that specialized services can be delivered to the children in need. Despite the progress in assessment that has been made by Agencies G and L, their classification tool also has limitations. In particular, their classification is mainly based on the risk factors children experienced. For example, Agency L has given the same weightings to children's psychological status and family's resources. A child suffering from psychological problems may need more resources and services than children whose family has less resources. Therefore, the classification of children's vulnerabilities might be inaccurate. It would be better to classify children using similar screening criteria of risk factors.

\section{Conclusions and Implications}

Accurately assessing child vulnerability and needs is an important part of practical social work. In order to deliver services to where they are needed most, different agencies in China (e.g., INGOs, government agencies and local social work organizations) utilize different tools to assess children's needs. This study reviewed the advantages and disadvantages of these assessment tools by discussing their coverage, quality, effectiveness and comprehensiveness.

To achieve a more effective assessment of vulnerable children, future research should examine the following areas. First, some indicators of the assessment tools have not been clearly designed and 
need to be refined in the future. For example, some indicators were ambiguously defined, and some indicators overlapped. This might confuse social workers when conducting an assessment, therefore reducing its accuracy. Obviously, assessment outcomes are closely associated with the follow-up delivery of services. Therefore, inaccurate assessment of specific factors will negatively impact the delivery of appropriate services to vulnerable children.

Second, while a simplified tool has the advantage of implementing a quick assessment, it might miss key information concerning a child's vulnerabilities. As a result, required services and a relevant level of child protection may not be provided.

Third, a quick simple classification does not permit identification of children affected by differing risk factors (e.g., differences between severely ill children and children without proper care). For example, it is hard to compare the extent of vulnerabilities between children who were ill and children whose parents lack the ability to provide care. In this case, using one overarching classification criteria for screening out high risk child cases may not be accurate and cause problems of mismatch. It is not sensitive enough to differentiate the challenges or risk factors faced by children. Therefore, it is recommended to use a corresponding classification criteria based on risk factors.

This study also has implications for service providers. For example, when identifying child risk levels and assessing children' needs, using a multi-level comprehensive assessment tool on children's context would be helpful for service delivery. A comprehensive assessment tool considers children's vulnerabilities more thoroughly. The challenges faced by children were easier to be identified and thus corresponding services and resources can be delivered directly. We therefore suggest that the criteria of "evaluating whether an assessment tool is comprehensive" should be considered as a more important benchmark for developing assessment tools. Finally, it is recommended that social workers in this field be given more comprehensive training when conducting assessments.

Author Contributions: Conceptualization, D.Q.; Data curation, D.Q.; Formal analysis, D.Q.; Funding acquisition, D.Q.; Investigation, D.Q.; Methodology, D.Q. and S.W.; Validation, S.W.; Writing - original draft, D.Q. and S.W.; Writing-review \& editing, S.W. All authors have read and agreed to the published version of the manuscript.

Funding: The authors of this paper are grateful to the following funding sources for support of the research project: National Natural Science Foundation of China Project (71804041), National Social Science Fund Youth Project (17CSH051) the Jiangsu Province Social Sciences Project (20185061611) and the United Nations Children's Foundation Project (43267495).

Conflicts of Interest: The authors declare no conflict of interest.

\section{References}

Arbeiter, Ere, and Karmen Toros. 2017. Parental engagement in child protection assessment: A qualitative analysis of worker and parent perspectives. International Social Work 60: 1469-81. [CrossRef]

Creswell, John W. 2012. Qualitative Inquiry and Research Design: Choosing among Five Approaches, 3rd ed. Thousand Oaks: Sage.

Darlington, Yvonne, Karen Healy, and Judith A. Feeney. 2010. Approaches to assessment and intervention across four types of child and family welfare services. Children and Youth Services Review 32: 356-64. [CrossRef]

Flyvbjerg, Bent. 2006. Five misunderstandings about case-study research. Qualitative Inquiry 12: 219-45. [CrossRef]

Gambrill, Eileen, and Aron Shlonsky. 2000. Risk assessment in context. Children and Youth Services Review 22: 813-37. [CrossRef]

Glaser, Barney G., and Anselm L. Strauss. 1967. The Discovery of Grounded Theory: Strategies for Qualitative Research. Chicago: Aldine.

Guidelines of the Child Welfare Pilot Project. 2014. Guidelines of the Child Welfare Pilot Project-Questions about Child Welfare Social Workers. Beijing: Child Welfare Research Centre.

Johnson, Michelle A., Susan Stone, Christine Lou, Catherine M. Vu, Jennifer Ling, Paola Mizrahi, and Michael J. Austin. 2008. Family assessment in child welfare services: Instrument comparisons. Journal of Evidence-Based Social Work 5: 57-90. [CrossRef] [PubMed] 
Léveillé, Sophie, and Claire Chamberland. 2010. Toward a general model for child welfare and protection services: A meta-evaluation of international experiences regarding the adoption of the Framework for the Assessment of Children in Need and Their Families (FACNF). Children and Youth Services Review 32: 929-44. [CrossRef] Ritchie, Jane, Jane Lewis, Carol McNaughton Nicholls, and Rachel Ormston, eds. 2013. Qualitative Research Practice: A Guide for Social Science Students \& Researchers. Thousand Oaks: Sage.

Rosanbalm, Katie D., Elizabeth H. Snyder, C. Nicole Lawrence, Kanisha Coleman, Joseph J. Frey, Johanna B. van den Ende, and Kenneth A. Dodge. 2016. Child wellbeing assessment in child welfare: A review of four measures. Children and Youth Services Review 68: 1-16. [CrossRef]

Smithgall, Cheryl, Elizabeth Jarpe-Ratner, Natalya Gnedko-Berry, and Sally Mason. 2015. Developing and testing a framework for evaluating the quality of comprehensive family assessment in child welfare. Child Abuse $\mathcal{E}$ Neglect 44: 194-206. [CrossRef]

State Council. 2016. Guideline on Protection of Vulnerable Children in China. Beijing: State Council of People's Republic of China.

Toros, Karmen. 2016. Child protective workers' reflections on principles underpinning the assessment of children in need: The case of Estonia. International Social Work 60: 1255-67. [CrossRef]

Välba, Egle, Karmen Toros, and Anne Tiko. 2017. Family engagement within the context of assessment in child protection practice: The case of Estonia. Child E Family Social Work 22: 1506-14. [CrossRef]

Wu, Shiyou, Diane C. Wyant, and Mark W. Fraser. 2016. Author guidelines for manuscripts reporting on qualitative research. Journal of the Society for Social Work and Research 7: 405-25. [CrossRef]

(C) 2020 by the authors. Licensee MDPI, Basel, Switzerland. This article is an open access article distributed under the terms and conditions of the Creative Commons Attribution (CC BY) license (http://creativecommons.org/licenses/by/4.0/). 